1 Britton JR. Effects of social class, sex, and region of residence on age at death from cystic fibrosis. Br Med f 1989;298:483-6 . (25 February.)

2 Penketh ARL, Wise A, Mearns MB, Hodson ME, Batten JC. Cystic fibrosis in adolescents and adults. Thorax 1987;42: 526-32.

3 Littlewood JM, Kelleher J, Rawson I, et al. Comprehensive assessment of patients at a CF centre identifies suboptimal treatment and improves management, symptoms and condition of patients. In: Proceedings of the lOth international cystic fibrosis congress, Sydney, Australia, 1988. Hong Kong: Excerpta Medica, 1988. (Asia Pacific congress series No 74 . 4 Office of Population Censuses and Surveys. West Yorkshire county census report. London: HMSO, 1981

\section{Changing character of cervical cancer in young women}

SIR, - Whether or not the behaviour of invasive cervical cancer is changing has been extensively debated over the past few years and remains contentious. We consider that the conclusions of Dr P M Elliott and colleagues are not justified by the data presented.

One of the main problems with any study that attempts to define changing trends in the incidence and biological behaviour of a tumour is that of defining a representative population of patients on which to base the analysis. Inevitably, the study of population based data is required because referral practice to any single institution may be subject to many external influences that bias results. Although a single institution that has a captive population and receives all referrals of a particular type of tumour may justifiably report on trends in incidence and prognosis, this will rarely be the case for tertiary referral centres such as the King George V Hospital, Sydney. There seems little doubt that the incidence of invasive cervical carcinoma in young women has increased in recent years. ${ }^{2}$ As Dr Elliott and colleagues report only the percentages of women aged under 35 their data could just as easily represent a decrease in the number of older women referred.

Referral patterns are particularly relevant when considering changes in the proportion of patients with affected nodes with early stage disease or the proportion of rare tumour types. The reported increase in affected lymph nodes in young women with stage Ib or IIa tumours may reflect only differences in other prognostic factors. It is also not clear from Dr Elliott and colleagues' paper whether histopathological review refers to a contemporary review for the analysis presented or to the fact that all tumours were examined by the pathologists at the time of presentation. In the light of recent interest in the prognosis of different types of tumours this is of fundamental importance. Changes in incidence may reflect increased awareness of rare types of tumours. In addition, Dr Elliott and colleagues state that preoperative intracavitary irradiation was the treatment of choice before 1969. The effect of this on histopathological assessment of tumour type must cast doubt on any conclusions regarding changes in the proportion of uncommon tumours.

Dr Elliott and colleagues go on to report the results of a Cox regression analysis performed on their data. Their description of the analysis is incomplete and does not state which, if any, prognostic factors other than age, stage, and node state were considered. Their finding that both node state and stage were of independent prognostic importance, whereas age ceased to be significant after controlling for node state, may be due to small numbers of patients or failure to consider other potentially important variables. In an analysis of cervical cancer in the total female population of our region, comprising 10022 cases over 25 years, Meanwell $e t$ al found that after other variables had been controlled for young age had a small positive or beneficial effect on survival. We have recently completed an analysis of 141 patients with surgically managed stage I or IIa cervical carcinoma and found that after stratification for depth of cervical invasion node state was not important for prognosis. Stage of the tumour and the presence of lymphatic and vascular invasion also had independent prognostic importance (unpublished data)

Finally, the authors report an increase in recurrence rates in younger patients without affected nodes in recent years, which prompted them to consider changing their treatment policy. Though we agree that medical audit with review of the results of treatment and consideration of new therapeutic approaches is important, we suggest that the analysis presented does not justify more intensive and toxic adjuvant treatment in "younger patients regardless of pelvic node state." It should be emphasised that the authors are considering a radical change in treatment policy based on six recurrences in 13 patients.

E J BUXTON N S A STUART

K A KELLY G R P BLACKLEDGE

West Midlands Cancer Research Campaign

Clinical Trials Unit, Queen Elizabeth Hospital,

Birmingham B15 2TH

1 Elliott PM, Tattersall MHN, Coppleson M, et al. Changing character of cervical cancer in young women. $\mathrm{Br}$ Med $\mathcal{F}$ 1989;298:288-90. (4 February.)

2 Meanwell CA, Kelly .KA, Wilson S, et al. Young age as a prognostic factor in cervical cancer: analysis of population based data from 10022 cases. Br Med f 1988;296:386-91.

\section{Prevalence of diabetes in a predominantly Asian community}

SIR, - Dr D Simmons and colleagues' present data that suggest that the high prevalence of known diabetes in Asian subjects ${ }^{2}$ is not explicable in terms of a higher detection rate. They state that overall less than a third of the total of all ascertained diabetic subjects had not been previously diagnosed and suggest that because of opportunistic case finding the estimate that half of all diabetic subjects in the population are undiagnosed may no longer be correct. They claim that theirs is the first population based screening programme since the Bedford study in 1962.

The Islington diabetes survey was a general practice based screening study of 1084 subjects aged over 40 , in which a capillary blood glucose concentration was estimated 2 hours after the subjects ingested the equivalent of $75 \mathrm{~g}$ glucose. ${ }^{4}$ The prevalence of newly diagnosed diabetes in the study was $2 \cdot 6 \%$ (95\% confidence interval $1.63 \%$ to $3.57 \%$ ) and the prevalence of previously known diabetes $2 \cdot 0 \%(1 \cdot 54 \%$ to $2 \cdot 48 \%)$, ${ }^{+}$suggesting that even after the change in diagnostic criteria for diabetes mellitus, ${ }^{6}$ half of all diabetic subjects are undiagnosed.

Prevalence of known and previously diagnosed diabetes in white and Asian subjects

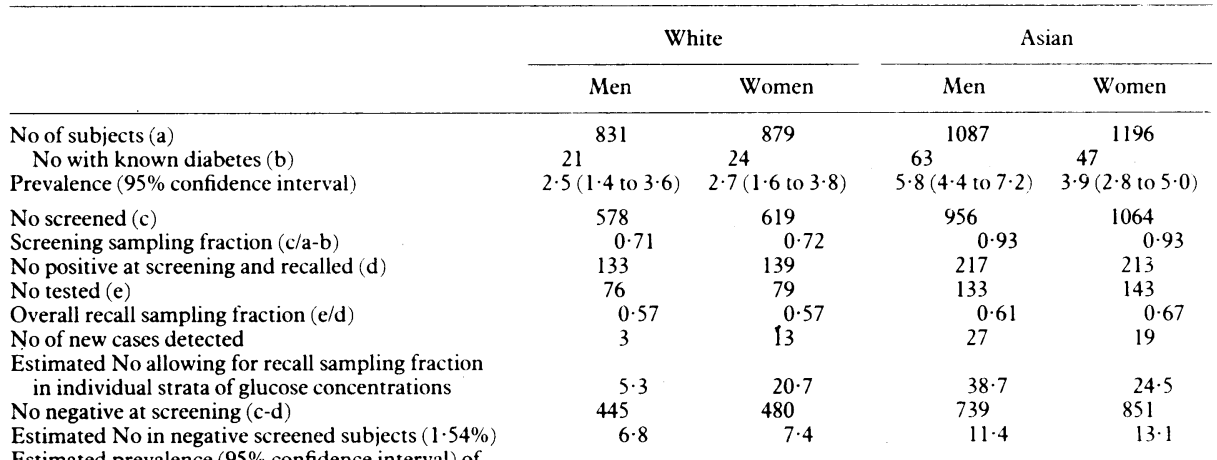

Estimated No in negative screened subjects (1.54\%) Estimated prevalence $(95 \%$ confidence interval) of undiagnosed diabetes allowing for sensitivity of screening test and sampling fractions
The calculation of confidence intervals for differences in proportions in table I of Dr Simmons and colleagues' paper seems to be in error because in several instances the lower limit should have been negative rather than zero. Moreover, the calculation of the prevalence of previously undiagnosed diabetes in their study is by its nature a minimum estimate because the prevalence has not been adjusted for the rate of false negatives ( 2 Calculation of the true prevalence of previously undiagnosed diabetes is hampered by the mismatching of numbers between tables I and II and between the tables and the text but has been attempted in our table. The estimates of prevalence of previously undiagnosed diabetes have been made with the individual recall sampling fractions in the separate strata of glucose concentrations at screening given in their table II. The confidence intervals have been calculated by adapting the method of Woolf. ${ }^{i x}$

From this table, the overall prevalences of known and previously undiagnosed diabetes in white subjects are $2 \cdot 6 \%(1 \cdot 9 \%$ to $3 \cdot 4 \%)$ and $3 \cdot 2 \%$ ( $1.4 \%$ to $5.0 \%)$, respectively, and in Asian subjects are $4 \cdot 8 \%(3 \cdot 9 \%$ to $5 \cdot 7 \%)$ and $4 \cdot 1 \%(2 \cdot 4 \%$ to $5 \cdot 8 \%)$ respectively. Although the confidence intervals are wide, there is little evidence from these data that substantial differences exist between the prevalences of known and of newly diagnosed diabetes in either ethnic group.

We thank Martin Shipley for his statistical advice.

JOHN YUDKIN CAROLINE A JACKSON RICHARD D FORREST

Academic Unit of Diabetes and Endocrinology,

Whittington Hospital,

London N195NF

1 Simmons D, Williams DRR, Powell MJ. Prevalence of diabetes in a predominantly Asian community: preliminary findings of the Coventry diabetes study. Br Med f 1989;298:18-21. (7 January.)

Mather HM, Keen $\mathbf{H}$. The Southall diabetes survey: prevalence of known diabetes in Asians and Europeans. Br Med $\mathscr{f}$ 1985;291:1081-4

Sharp CL, Butterfield WJH, Keen H. Diabetes survey in 1964;57:193-202.

4 Forrest RD, Jackson CA, Yudkin JS. Glucose intolerance and Diabetic Med 1986;3:338-42.

5 Forrest RD, Jackson CA, Yudkin JS. The glycohaemoglobin assay as a screening test for diabetes mellitus. The Islington diabetes survey. Diabetic Med 1987;4:254-9.

6 World Health Organisation Expert Committec on Diabetes Mellitus. Second report. WHO Tech Rep Ser 1980; No 646.

7 Woolf B. On estimating the relationship between blood group and disease. Ann Hum Genet 1955;19:251-3. myocardial infarction to glycohaemoglobin levels. Diabetologic 1988;31:201-5.

AUTHORS' REPLY, - The Islington diabetes survey mentioned by Dr Yudkin' was a general practice $130,1.54 \%)$ in the screening test employed. Bedford 1962. Proceedings of the Royal Society of Medicine

Yudkin JS, Oswald GA, McKeigue PM, Forrest RD, Jackson $\mathrm{CA}$. The relationship of hospital admission and fatality from 